\title{
Participatory Practice in Zambia: Pitfalls and Hopes for Tomorrow
}

\author{
Daniel L. Mpolomoka ${ }^{1}$, Musonda Luchembe ${ }^{2}$, Selina Banda ${ }^{1}$, Peter Sampa ${ }^{3}$, Stabile Namwai Ngambi $^{3} \&$ Maria \\ Lungowe Mundia ${ }^{4}$ \\ ${ }^{1}$ Zambian Open University, Zambia \\ ${ }^{2}$ Department of Adult Education and Extension Studies, University of Zambia, Zambia \\ ${ }^{3}$ University of Zambia, Copperbelt Province, Zambia \\ ${ }^{4}$ Quality Assurance and Extension Studies, Zambian Open University, Zambia \\ Correspondence: Daniel L. Mpolomoka, Lecturer, Zambian Open University, School of Education, P.O Box \\ 31925, Newfoundland Campus, Lusaka, Zambia.
}

Received: June 23, 2018

doi:10.20849/aes.v3i3.476
Accepted: September 18, 2018

Online Published: September 26, 2018

URL: https://doi.org/10.20849/aes.v3i3.476

\begin{abstract}
This paper is informed by findings of a study which sought to explore citizen participation in Zambia. The paper used a phenomenological design. Qualitative data was collected and analysed using emerging themes. The results revealed that many Zambian citizens do not participate in developmental and economic activities, projects and programmes due to lack of development prevailing in most parts of the country, and in particular the high levels of economic stress that are felt at individual and household levels. The inability to implement the sound choices and policy decisions craft by central government though a number of policies, ratifications and deliberate initiatives that the country has assented to, aimed at encouraging participatory practice. This has also caused citizens to lose trust in legislatures. At local level, the majority of citizens have inadequate access to basic social and economic services to live dignified lives. Government's inability to provide such services has made citizens not to see the need to participate in any developmental programmes. With all such situations, Zambian citizens are discouraged to participate in the governance of the country and therefore, participatory practices fail.
\end{abstract}

Keywords: participation, practice, citizens, government

\section{Introduction}

This paper provides insight into the dilemma of participatory practice in Zambia. The backdrop, objectives are given first and thereafter the contextual understanding of participatory practice, a theoretical framework and findings, in form of thematic phenomenological exposition of participatory practice in Zambia is presented. In the end, conclusion and recommendations are made.

\section{The Backdrop}

In Zambian communities, citizen participation in community and national activities, projects, programmes and governance is minimal and difficult to measure. This is happening at a time when the government has put in place deliberate mechanisms to influence citizens to participate in decision making, especially at community, district and national levels countrywide. As a result, the low participation in community and national development projects has given birth to numerous problems.

\section{Objectives}

The objectives of the study are to

1. Identify the pitfalls in the participatory practices in Zambia

2. Establish what needs to be done to eliminate participatory practices pitfalls

3. Describe hopes for participatory practices in Zambia

\section{Contextual Understanding of Participatory Practice}

The term participatory practice refers to education, management and or community involvement. Participatory education is a collective effort in which the participants are committed to building a just society through individual and social economic transformation ending domination through changing power relations, (Pat 
Campbell, 2010).

Sauve (1987) states that participatory education is a learning/teaching process where in all participants are involved in and committed to defining their own learning needs and wants, working out an approach to addressing them and evaluating that process as they live out of and into it all within the context of making life better for themselves and those around them.

This was emphasised by Jurmo, (1987) who stated that participatory practices provide opportunities for learners to engage in democratic decision making which lead to a more efficient program responsive to learners' needs. Participatory practices enhance critical thinking, self-esteem and the ability to work collaboratively with others.

In addition, participatory practices involve communities into the design, implementation and evaluation of development projects and programmes as a way for increasing their ownership and greater sustainability. Furthermore, some participatory processes have claimed to be contributing to the increased accountability of the aid and to the empowerment of the poor and marginalised people, (Chambers, 1997).

Participatory practices seek to bring more people-centred approach to the development practice by laying emphasis on people's active role in pursuing their own agendas and having more power in decision making processes as they are the ones who know most about their lives. Chambers, $(2002$,$) states that participatory$ practices are widely used by NGOs, academics, governments and communities because they enable and empower people to share, analyse and enhance their knowledge of life and conditions, and to plan, act, monitor, evaluate and reflect.

\section{Theoretical Framework}

This study is informed by Paulo Freire's theory of conscientization (Freire, 1970). The theory of conscientization is used as a foundation of understanding participatory practice. The theory talks about a process were disadvantaged and marginalized groups of people move from an uninformed position to an informed position, thereby creating the conditions for the transformation of society in accordance with social justice (McCowan, 2009). The process involves identifying problems being experienced by people through dialogue and becoming part of the process in improving the welfare of the community. It requires citizen's capacities that can be gained through general education such as literacy, oral and written expression, analytical skills, knowledge of history and current affairs.

The theory requires citizens to be enlightened as they will be able to understand their role in participatory practice in government projects and programmes. This will accord the community the opportunity to get involved (participatory practice) and also claim ownership. Inevitably, society can be organised in the best interest of all and that individual citizens can and will act for the common good. This paves way for community participation in decision making and also facilitates service delivery based on the community's needs.

\section{Methodology}

The study used a schulzian transcendental phenomenological design. Phenomenology looks into the spiritual nature of the social world, which must be interpreted and constructed in terms of the subjective understanding, which individual human agents ascribe to their social situations. Schultzian transcendental phenomenology is designed to focus on latent meanings of essences by giving them a description in the language of a social actor (Creswell, 2007; Moustakas, 1994; Lauterbach, 1993). The aim of the researchers was to describe as accurately as possible the phenomenon (participatory practice in Zambia), refraining from any pre-given framework, but remaining true to the facts.

Qualitative researchers tend to use inductive analysis of data, meaning that the critical themes emerge out of the data (Simon, 2011; Patton, 1990). Qualitative analysis requires some creativity, for the challenge is to place the raw data into logical meaningful categories; to examine them in a holistic fashion; and to find a way to communicate this interpretation to others.

\section{Findings and Discussion}

The research findings and discussion of findings were classified as themes as follows:

\subsection{Theme 1: Lack of Involvement in Development and Economic Activities, Projects and Programmes}

Among the challenges and dilemmas of participatory practice in Zambia is lack of involvement in development and economic activities, projects and programmes by the majority of citizens. One of the many factors, with a cyclic effect on peoples participation in development and political life, inter alia, has been the circumstances that citizens find themselves due to lack of development prevailing in most parts of the country, and in particular the high levels of economic stress that are felt at individual and household levels. Levi \& Sacks (2005) state that 
over 8 million of the 14 million population of the country are cited to live below the income poverty line while an additional 6 million which is nearly two thirds of the population, live in extreme poverty, unable to meet their basic food needs.

\subsection{Theme 2: Participatory Practice and Female Headed Households}

Female headed households are on the increase and challenges they face include food insecurity and health challenges because of a lack of access to land, technology, education and health services. Education especially among women influences household access to food and medicine by enabling individuals to acquire skills and make proper use of health care and other public services (Smith et al, 2005).

When citizens fail to meet their basic needs, they opt to disengage with political and political life to focus on their immediate individual needs. It manifests itself on the high levels of apathy and cynicism to democratic processes such as elections or indeed participation in community work and development projects. It also breeds uncertainty and insecurity amongst individuals. This scenario becomes a challenge and dilemma to participatory practice.

\subsection{Theme 3: Inability to Implement the Sound Choices and Policy Decisions}

This thematic area revolves around people in authority's (at ward, community, district and provincial levels) inability to implement the sound choices and policy decisions craft by central government. Sound choices and decisions about policy and resources are at the heart of a well-functioning government and its political processes. The government professes to be concerned with wealth creation, social protection, promoting human development and creating conditions that encourage economic development. Even when these aspirations are clearly articulated in national and sector development plans and other strategy documents, which strive to make good connections between economic and social policy, they are not actualised together with the grassroots.

In Zambia, there are a number of policies, ratifications and deliberate initiatives that the country has assented to, aimed at encouraging participatory practice. These include the following: the National Development Plans, Vision 2030, Sustainable Development Policies (e.g. Poverty Reduction, Millennium Development Goal, Sustainable Development Goals-2030) Implementing such reforms requires a clear policy framework, sound public expenditure management and strong political engagement. However, the nature of the political system determines policy, and the allocation of scarce resources between competing interests, including those of poor people. To the contrary, the production of policy statements does not represent a serious intention to implement policies. Poverty and vulnerability levels remained unacceptably high (World Bank, 2005). This has caused citizens to lose trust in legislatures. Thus, poor governance and policy implementation failures causes participatory practice to fail in Zambia.

\subsection{Theme 4: Governance and Its Effect on Participatory Practice}

The governance challenges and its effect on participatory practice cannot go without mention.

The government has failed to address the fundamental structural determinants of corruption and patronage as well as the impact these interrelated vices have on good governance. However, citizens' feelings about the government and its performance have been affected by a number of negative developments in the country. These include high levels of corruption within government, abuse of public resources, lack of accountability, abuse of office among many others.

One of the challenges of participatory practice includes non-involvement of people in the issues of governance. Many definitions of governance refer to how society manage natural, human and economic resources, social and institutional houses for the enhancement of individuals and national development. People want to be citizens, not merely passengers, spectators, voters and consumers. As citizens, they have rights and obligations, they want their rights to be respected and they also want to fulfil their obligations. Citizens now demand a greater say in shaping their lives. They are asking for a full, active and greater role in decision- making. They want to participate in discussions and decisions pertaining to the governance of society. They want to know why some policies are not implemented and also why some people or political leaders are above the law. They demand for participatory and responsible governance by fellow citizens. Mbewe (2010: 13) contends that

Participation by both men and women is a cornerstone of good governance. Participation could be either direct or through legitimate intermediate institutions or representatives. It is important to point out that representative democracy does not necessarily mean that the concerns of the most vulnerable in society would be taken into consideration action in decision making, participation needs to be informed and organized. 
Participatory practices in Zambia also face some challenges in that the government is against certain NGOs which are involved in educating the people in various issues that concern them. For example, the Civil Society Organisations (CSO) advocates for the transformation of society so that all mankind can be equal. The poor are empowered so as to make their voices heard like their rich counterparts. The illiterates are educated so that they can also participate in the activities that their counterparts do.

\subsection{Theme 5: Failure to Take up Participatory Practices}

Zambians fail to take up participatory practices due to lack of facilities to effectively disseminate government policies across the country. While there is general lack of communication facilities in most parts of the country, over the years, government has not effectively availed or developed infrastructure to support information and communication needs across the country. The public radio and television facilities as at present do not cover the entire country. To this effect, government cannot easily disseminate or in reverse access information that is critical to interacting with citizens across the country or indeed inform its strategic decision-making. The knowledge and information gap is very evident as one goes across rural communities, and this is not only confined to the general citizenry but includes public servants who would ordinarily be expected to explain and inform the citizens on what is happening within and out of the districts or the nation as a whole.

\subsection{Theme 6: Low Literacy Levels}

The already noted information flaws seem to aggravate the seemingly low literacy levels in how citizens engage government at different levels. Most information that citizens access is speculative, based on word-of-mouth, not factual and not thought-through. In the absence of such information it is further difficult to define or envisage what would be the basis on which already disadvantaged communities can interact with political and public service representatives at different levels.

In Zambia a number of citizens of the rural community are illiterate. This fact causes a number of them to be afraid of contributing and participating in issues of development in their environments. In the case of development with the people, task for outsiders became to hand over the stick, to empower local people, to enhance their confidence, to enable them to define, express and analyse their reality, and not to reflect that of the upper (outsider).

The illiteracy levels are higher among women and children. The ability of women to participate effectively in development oriented programmes is constrained by illiteracy and other factors such as excessive workload, problem of health, lack of time, teenage pregnancy, organisational problems, cultural patterns, customs and male attitudes (Osunde and Omoruyi, 1999).

The Government still struggles with accountability for public resources and inability to effectively deliver services. Albeit all this a Public Sector Reform Programme has been running since the 1990s aimed at restructuring the civil service to make it more efficient. Salaries in the civil service remain uncompetitive and generate serious human resource problems, (Institute for Democracy in Southern Africa [IDASA], 2006).

\subsection{Theme 7: Citizens Grappling to Meet Physiological Needs}

At local level, the majority of citizens have inadequate access to basic social and economic services to live dignified lives. There is general lack of adequate basic needs such as adequate food, clean water, education and health for most remote rural communities in Zambia. Inability of government to provide these services to be deemed accessible to citizens negatively affects citizens' views and perceptions of government effectiveness. As a result citizens do not see a need to participate in any developmental programmes.

The manner of programme implementation, which ultimately affects both quality and adequacy of public goods and services, is that government operates a highly centralized system of governance and public service delivery, whose decisions are largely directed by the Lusaka headquartered government ministries and agencies. The delivery is through concentrated, local structures of central government ministries/institutions, many times by passing or not coordinating with local government structures.

The services expected to be implemented by local government through the various municipalities and districts are inadequate due to these district councils not having adequate local resources and delayed or inadequate development grants from the central government. In summation, the end-users of these public goods and services do not access adequate or timely services which means that their livelihood circumstances remain unchanged, and in many instances deteriorating.

The educational sector has not been spared, funding by government is so inadequate. We have dilapidated infrastructure. The states of classroom blocks, floors, black board, desks are unacceptable. There are inadequate 
teaching and learning materials. Teacher's houses and staff rooms in their workplace are in deteriorating states.This has left the teachers in a state of demonization even to participate in national deployment maters. As a matter of fact due to poor remuneration and conditions of service a good number of educationalists have left the profession to pursue other careers and others have left the country to offer services in other countries. This process of brain drain has robed the country of able minds to contribute to community, societal and national development (CCZ, 2015).

Brain drain has been the order of the day in Zambia due to the dysfunctionality of many social, community and national sector. This has hindered participatory practice due to the fact that there is loss of intellectual power and capacity to participate in policy formulation, implementation and evaluation.

\subsection{Theme 8: Skewed Distribution of Services Across Individuals and Regions}

Currently in Zambia there exists a skewed distribution of services across individuals and regions in the country, vulnerability to economic and financial crises, and the overlapping deprivations suffered by many. Rural provinces of Zambia have over a long period of time remained under-developed with its people not accessing electricity, clean water (drinking water from access points that animals also access; from wells; eating wild fruits that animals eat), having poor sanitation and poor health care service provision. Though there is greater attention emerging to address these concerns, this has had the net effect of seriously affecting the inhabitants of these regions who inevitably become disillusioned and contend that government least cares for them.

The National Decentralization Policy which was adopted in 2004 aims at a fully decentralized and democratically elected system of governance characterized by open, predictable and transparent policy-making and implementation processes. The slow pace at which decentralization implementation is taking place in the country has had serious implications on how government engages with citizens, and facilitates for them to take leadership in shaping local development and governance, (Political Governance in Study in Zambia, 2013).

Government has used the issue of lack of capacity particularly fiscal capacity, to explain the slow pace which characterises the implementation of the decentralization policy. Surprisingly, there has not been much concerted effort on the part of civil society to advocate for decentralization. This is difficult to understand in view of the importance of decentralization to the delivery of quality and responsive services.

In the absence of such a process, development approaches remain top-down and do not facilitate for engagement with local communities. The ability of people and their institutions to participate in decisions that affect them, and the power they possess to influence change are important for sustainability.

\subsection{Theme 9: Poorly Developed and Lack of Reaching out Transport and Communication}

Poorly developed and lack of reaching out transport and communication infrastructure is among the dilemmas and challenges of participatory practice in Zambia. Zambia's development process requires the support of varied state infrastructure. Transport and communication infrastructure, among others, are central to delivery mechanism in the generation of quality socio-economic development, (Ministry of Finance \& National Planning, 2010). In addition, Weber (1976) also noted that, "Until roads spread, many rural communities remained imprisoned in semi-isolation, limited participants in the economy and politics of the nation. Currently, the road and communication infrastructure has not penetrated all parts of the country.

The current Zambian governance system does not take on board everyone. There is need for more participation but the pressure has to come from the people themselves. For example, the constitution is known by the elite only while the majority do not know it. The current Electoral system is not yielding the intended results for the people to appreciate the system. The disparities between individual leaders and their constituencies in terms of development are very high giving an impression that politics especially roles such as being an Member of Parliament is meant for one to access wealth and political power, and not to be of service to the communities they ought to be representing.

\subsection{Theme 10: Political Culture}

The prevailing political culture in Zambia shows high levels of intolerance, characterised by mudslinging, especially during election periods, and unfortunately, while many people expected this to go down after the holding of the 2011 Elections, the trend has continued. In some instances, this perceived intolerance being practiced by all political players in and out of government, affects the quality of governance to the extent that critical issues of development are not being pursued to the detriment of the majority of the citizens who want to see improvement in their way of life. With all these situations, citizens are discouraged to participate in the governance of the country and therefore, participatory practices fail. 
There are still challenges of citizen participation in community and national activities, projects, programmes and governance in Zambia as measures have not had major impact on strengthening their (citizen) participation. Albeit all this, the government has initiated deliberate mechanisms to influence citizens to participate in decision making. Decision making has been deliberately left in the hands of selected few 'civic leaders' and 'community representatives' who champion their selfish interests and not those of the represented. They also lack systematic and deliberate community systems of tapping concerns, views, propositions, activities, projects and programmes. Such 'bottom-up' civic and community leadership style and decision making approach does not prevail. Instead, they espouse the 'top-down' leadership style and decision making approach. In addition, service delivery to the communities has not improved. Sakala (2008) attributes the failures of past or current polices on citizen participation "to lack of capacity of local authorities at both the institutional and individual levels, an inadequate legal and fiscal framework, political and administrative will, inadequate private or public sector participation and in some cases unabated corruption."

\section{Conclusion}

There are various factors that have been identified on having a bearing on the extent to which citizens can be engaged to participate on one hand, and factors that impede their participation in community and national activities, projects and programmes. The paper has revealed that citizens face challenges when participating in community and national activities, projects, programmes and governance in Zambia. This is primarily because the government has not initiated deliberate mechanisms to influence citizens to participate in decision making. The paper further contends that decision making has been deliberately left in the hands of selected few 'civic leaders' and 'community representatives' who champion their selfish interests and not those of the represented; and lack systematic and deliberate community systems of tapping concerns, views, propositions, activities, projects and programmes.

\section{References}

CCZ. (2015). Social Accountability in the education and Health Sector. Lusaka Council of Churches in Zambia.

Creswell, J.W. (2009). Research Design: Qualitative, Quantitative, and Mixed Methods Approaches (3rd ed.). Thousand Oaks. CA: Sage.

Eugen Weber. (1976). Peasants into Frenchmen: The modernization of Rural France, 1870-1914. Stanford: Stanford University.

Freire, P. (1970). Pedagogy of the oppressed. New York: Herder and Herder.

Lauterbach, S.S. (1993). In another world: A phenomenological perspective and discovery of meaning in mothers' experience with death of a wished-for baby: Doing phenomenology. In P.L. Munhall \& C.O. Boyd (Eds.), Nursing research: A qualitative perspective (pp. 33-179). New York: National League for Nursing Press.

Ledwith, M., \& Janet, M. (2010). Participatory practice: Community based action for transformative change. Bristol: Policy Press University.

Levi, M., \& Sacks, A. (2005). Achieving Good Government and, Maybe, Legitimacy. New Frontiers of Social Policy. Arusha Conference.

Mbewe, T. (2011). Introduction to Governance (Module). Lusaka, Zambian Open University.

McCowan, T. (2009). Rethinking Citizenship Education: A Curriculum for Participatory Democracy. Continuum International Publishing Group, London: New York.

Ministry of Finance \& National Planning. (2010). Sixth National Development Plan. Lusaka: Government of the Republic of Zambia.

Moustakas, C. (1994). Phenomenological research methods. Thousand Oaks, CA: Sage. https://doi.org/10.4135/9781412995658

Patton, M.Q. (1990). Qualitative Evaluation and Research Methods. (2nd ed.). Newbury Park, CA: Sage Publications, Inc.

Sakala, J. (2008). Strengthening Local Government for Effective Citizen Participation. Lusaka: Local Government Association of Zambia.

Simon, M.K. (2011). Dissertation and scholarly research: Recipes for success. Lexington, KY: Dissertation Success, LLC. Retrieved from www.dissertationrecipes.com 
Smith, et al. (2005). Why Is Child Malnutrition Lower in Urban Areas Than in Rural Areas?. Evidence from 36 Developing Countries. World https://doi.org/10.1016/j.worlddev.2005.03.002

Development, $\quad 33(8)$,

1285-1305.

World Bank. (2005). Poverty and Vulnerability Assessments. Zambia.

\section{Copyrights}

Copyright for this article is retained by the author(s), with first publication rights granted to the journal.

This is an open-access article distributed under the terms and conditions of the Creative Commons Attribution license (http://creativecommons.org/licenses/by/4.0/). 